\title{
A CRITICAL ANALYSIS OF THE IMPACT MEASUREMENT IN IMPACT FINANCE
}

\author{
Luca Piras *
}

* Department of Economics and Business Sciences, University of Cagliari, Italy

Contact details: Department of Economics and Business Sciences, University of Cagliari, Via Sant'Ignazio da Laconi, 1709126 - Cagliari, Italy

\begin{abstract}
OPEN 2 ACCESS
Abstract

How to cite this paper: Piras, L. (2019). A critical analysis of the impact measurement in impact finance. Journal of Governance \& Regulation, 8(4), 56-63.

https://doi.org/10.22495/jgrv8i4art5

Copyright (c) 2019 The Authors

This work is licensed under a Creative Commons Attribution 4.0 International License (CC BY 4.0).

https://creativecommons.org/licenses/by/ $4.0 /$

ISSN Print: 2220-9352

ISSN Online: 2306-6784

Received: 13.10 .2019

Accepted: 26.12 .2019

JEL Classification: G1, G3, G4, D4 DOI: $10.22495 /$ jgrv8i4art5

Academic literature on impact finance has not yet covered all aspects of the topic, nor has significantly contributed, so far, to solve several relevant problems arising from the field. Defining the metrics and measurement models suitable to assess impact is probably, among them, the most important one. Practitioners seem willing to exploit the potential value and, although useful heuristics and practical solutions have been found, no satisfactory and widely accepted valuation model is available. The present paper tries to summarize the state of the art, through the analysis of the available literature and tries to address some possible development in future research. The underlying idea is that the field is still very new, on one side, and extremely diverse in its manifestation, therefore no traditional theory fully applies to it. At the same time, the research on the topic still relays on practitioners' effort, rather than on academia, a gap that ought to be filled. The paper concludes that Impact Finance and Investing are perhaps too narrow labels that limit the possibility to fully grasp the core of it and propose to widen up it by using "Positive Finance" as a more comprehensive one. Indeed, it has been found that academic empirical studies are so far very few and statistical findings far from being robust. The absence of accepted market models, prevent researchers from delivering a theoretical effective interpretation of the growing market.
\end{abstract}

Keywords: Impact, Measures, Metrix, Impact Finance, Impact Investing

Authors' individual contribution: The author is responsible for all the contributions to the paper according to CRediT (Contributor Roles Taxonomy) standards.

\section{INTRODUCTION}

Among the many common sayings about finance, one of the most frequent is: "Finance is everywhere". It is probably true since the logic of finance and its underlying ideas are general enough to be useful in a very wide range of decisional problems. At the same time, particularly in complex decisional contexts, the combination of such logic with the broad variety of instruments and tools may generate an intricate framework, not always fully dominated by individuals, who fail in their attempt to make proper decisions.

Hence, in the struggle to act rationally, individuals put relevant effort into measuring the consequences of their decisional processes, mainly due to the choice of the proper metrics, not always available, rather often incomplete and unprecise. This is also one of the main tasks of science: "Measure what can be measured and make measurable what cannot be measured" (Galilei, 1632).

After almost four hundred years, scientists have learned how to measure numerous important aspects of the physical context and have made significant progress even in measuring human and social phenomena, such as economic and financial facts. Still, it is sometimes frustrating to realize how complicated it is to develop and use proper metrics in social sciences, particularly when the specific field of interest is new and disagreement among participants to the debate, largely overwhelm agreements.

This is the case of impact investing. Impact investing is considered by some an autonomous asset class and is characterized by the pursuit of social or environmental goals, along with economic and financial profits. This latter aspect turns out to be crucial in considering Impact Investing instruments as an autonomous asset class. 
Typically, an asset class represents a category of securities or other assets sharing common cash flow dynamics for any given state of the economy. As a consequence, all assets in any given class ought also to share a common risk profile. As stated by the CFA definition they should match five key criteria:

- include a relatively homogeneous set of assets;

- be mutually exclusive (have a rather unique combination of expected returns and risk profile);

- be diversifying (read "negative or very low correlation with other classes");

- as a group, make up a preponderance of worldwide investable wealth;

- have the capacity to absorb a significant fraction of an investor's portfolio without seriously affecting the portfolio's liquidity.

Therefore, if the idea of an autonomous asset class can be accepted, there are three dimensions that require proper metrics: 1) the expected return; 2) the risk profile; 3) the impact.

Since the first two have been studied widely and thoroughly in the past sixty years, this paper will focus on and try to analyze the current literature in order to identify which metrics are most widely accepted, so far, and which main issues remain to be solved to define an effective theoretical framework suitable for the third: the impact.

The paper will discuss the general framework for impact investments and finance, defining main features and differences with traditional finance. It will then discuss the main difficulties in enhancing and measuring impact metrics and how such metrics can influence the risk profile of underlying securities. The most accepted models and approaches will then be presented and critically revised.

\section{THE IMPACT FINANCE: LITERATURE REVIEW}

Impact finance encompasses the various investing activities that intentionally and explicitly aim to achieve a positive and measurable long-term impact on social and/or environmental issues. The metrics problems arise directly from the definition and include both the impact and the expected returns.

As far as the latter is concerned, the most important distinction to be made is between impact investing and "simple" charity or mere philanthropy. Seeking a financial return makes the difference; hence pursuing a value creation ought to be the main trait of such ventures. As pointed out by Grabenwarter and Liechtenstein (2011) five main features should be recognizable in impact investing:

- investors seeking value creation;

- the existence of a positive correlation between value creation and impact;

- the desired impact must be clearly identified and declared;

- the desired impact must be measurable;

- the final result must be the activation of the structural net improvement in social or environmental conditions.

The first question, which arises, concerns the proportion of profit seeking and impact (Hochstadter \& Scheck, 2015). From a subjective point of view, the most common distinction is between "financial first" investors, who give their preference to expected returns and will evaluate investment with higher returns, and "impact first" investors, who will, instead, privilege the impact goals of the venture.

Due to the fast growth in demand (GIIN \& IRIS, 2019), significant development of financial instruments has occurred (Nicholls \& Tomkinson, 2015; Rizzello, Carè, Migliazza, \& Trotta, 2016; Schinckus, 2017). Typically, an SPV will intermediate between funds providers and social investors; an independent evaluator will estimate the impact and financial returns and, eventually, share results among participants.

Investors shall resolve five trades-offs in their decision-making:

1) Expected Returns/Risk;

2) Socially responsible activities/any activity;

3) Sustainable activities/any activities;

4) Finance first/Impact first;

5) Philanthropy/financial return.

According to standard theory, investors should solve the trade-offs above only considering their time preferences and risk appetite. Such an approach includes, or perhaps takes for granted, that individual utility function integrates ethics in every decision, at least to the extent that ethics itself does not limit excessively the possibility of satisfying investors' prospects.

The possibility of properly and effectively measuring the expected impact, both ex-ante and expost plays a major role in driving investors' decisions (Spiess-Knafl \& Scheck, 2017). The most difficult thing to predict is the link between the projected investment and the desired social impact. Data availability, time span extension, the overall size of the social issue to be tackled, relevance and commitment of third parties to be involved are but a few of the issues.

\section{IMPACT MEASUREMENT: COMPLEXITY AND DYNAMISM}

Measurement problems and the correlated potential confusion deriving from them have largely stimulated the search for a suitable impact measurement method during the last decade. Differently from investments' financial performance measurements, social and environmental ones still face a variety of obstacles debated among scholars and practitioners, who have so far failed to establish a widely accepted and standardized method.

The social performance measurement proves to be a considerable challenge, due to the complexity associated with the demonstration of the social impact generation as well as its realization over time (Freeman \& Sherwood, 1965; Greenberg \& Mattison, 1955; Perret, 2008).

A key feature in such a debate is, therefore, "complexity". The main source of complexity is the diversity of social and environmental challenges; consequently, in the struggle to come up with a suitable set of metrics, the debate takes its steps from the study of adopted business models. Such a choice makes perfect sense, since business models are a synthetic representation of how a project produces, burns, and canalizes the cash flows to stakeholders. In impact investing the model emerges from a positive interaction between the financial and social purposes, specifying the types of impact investment the stakeholders are engaged in (Lévêque, Levillain, \& Segrestin, 2018).

Several studies (Lévêque et al., 2018; Maas \& Liket, 2011; GIIN, 2017) point out that organizations 
opt for measuring the outcomes in terms of market metrics and social approval. Still, the debate remains unsettled about the importance of the measurement of the outcome ${ }^{1}$ in improving the performance. Consequently, the core framework proposed is not and perhaps cannot be based solely on the outcomes. It should, instead, be a process composed of different phases carried out in different moments the first of which ought to be the operational mission setting - the broad framework linking performance measurement to the mission. The outcome should then be best captured when a pragmatic operational mission is established.

Metrics would then be shaped according to the conceptual background on which the impact venture is supposed to take place (Maas \& Liket, 2011). As a result, performance metrics and measures ought to be based on the explicit size of the targeted community or pre-identified issue, taking into account that the scale of the impact investment can and will evolve and expand over time as it succeeds to build its reputation and raise more funding.

A second dimension, the scope, is defined as the measure of the sphere of activities required to tackle the social or environmental need the organization is orientating its effort towards. Clearly defining scale and scope does not always prove to be easy or even possible and they often do not seem to make the perfect frame for the investment's impact as much as they are useful orientation tools to drive the organization's progress towards its operational mission.

Indeed, the impact itself does not have a single accepted definition. The common meaning given to the term is output; change; consequence or even externality. It can be easily referred to targeted individuals, communities or the society as a whole. Furthermore, impact investments can have an exclusively long-term impact, a short one, a medium and long-term impact, separately as well as jointly. However, impact as a concept can be restricted to one common aspect: it is the result that could not take place without a specific performed activity (Stievenart \& Pache, 2012).

Metrics (units) and methodology should then be designed to be - as much as possible - precise, simple and general, just as any metric applied to science should be. In this case, they should make it possible to overcome the simple description and accounting of the performed activity on one hand and the strictly economic performance measurement on the other. The complexity arising from such a multidimensional process may generate confusion in measurements, misleading investors' decisions. Facing these complexities, stakeholders may hesitate to engage in a process that is intrinsically incomplete, limited, inexact and questionable and that may, for all the previous reasons, be considered riskier than comparable traditional investments.

Mulgan (2010) claims that the main obstacle in measuring the social or the environmental impact is to consider that the value of the measured impact is supposed to be unbiased, sharp and stable. Whereas, once a social or environmental impact is addressed, it implies accepting the fact that the results obtained are biased, imprecise and variable as well as

\footnotetext{
${ }^{1}$ Outcome: "The intended or achieved short-term and medium-term effects of an intervention's outputs, usually requiring the collective effort of partners Completion of outputs and the achievement of impact". Cfr. OECD glossary (https://stats.oecd.org/glossary/)
}

assuming the consequences in terms of the uncertainty of estimations (Harari, 2016).

Delegating the environment (investors, target crowds, public administration, just to name some) to assess the value of any given impact venture, should allow the development of a flexible measurement method, though it seems, at the moment, impossible for the impact generated to be indisputable. Nevertheless, while the main objective is the impact measurement, in order to help investors and organizational policymakers make their decisions, these measurement limits do not seem to be considerably problematic as long as the stakeholders recognize it, whether expected or unexpected, direct or indirect, positive or negative.

Still, what is in a place represents a cognitive bias itself. In trying to align both pragmatism and rigor, generating an evident dissonance between the struggle to measure the social and environmental challenge using the same mind-set of accounting and financial measurement norms, which are, though, the fruitful result of decades of evolution, yet not concluded and even still developing, while being highly used by field's actors.

Setting suitable criteria would help solve the puzzle as Costa and Pesci (2016) propose:

- Relevance: questions, raised about the relevance of the measurement tool, are generally related to the priority of building a deeper knowledge and a broader understanding of the social and environmental needs being the origin of the business, in order to be able to explore its capacity to respond to these needs. Such a process enables managers to validate or develop, if necessary, the organizational mission, its objectives, and its actions.

- Effectiveness: it reflects the priority of fixing purposes and monitoring the extent to which they are being met. The gap analysis between the expected value and the enhanced one may reveal the organization's strengths and weaknesses, which represents an opportunity to improve performance. Investors tend to show high sensitivity to the level of progress to meet the pre-defined targets, especially if they are addressing social issues. This sensitivity may lead them to compare the impact of investment's performance over time and compare it to other comparable investments to ground their decision about the investment.

- Efficiency: it allows the focus to be placed on employed human and financial re-sources as terms of comparison for obtaining results in a "familiar" economic mental frame.

The impact evaluation is associated with multidimensional accountability as it may have different goals, also depending on the nature of the interactions taking place between the stakeholders and the impact investment. It can be conducted as a part of the accountability towards the shareholders or within the organization itself to help managers with the monitoring and the management of the organizational activities or to acquire the value of the impact created in the society.

Precisely identifying the object of the evaluation and the final destination of the measurement conducted, as easy as it seems to be, remains necessary in order to circumscribe the measurement method and the evaluation process. 


\section{THEORY OF CHANGE}

Examining the developed impact evaluating tools and metrics, the literature available so far includes several tools designed to enable managers to highlight the effects of impact investment activities in response to social needs that eventually are reflected by social changes, the so-called "theory of change".

The term "theory of change" derives from the program evaluation field. The theory is actually a visual representation of a model that encompasses the following components (Jackson, 2013):

- the logic behind the performed activities;

- the assumptions on which the investment model is constructed;

- the endogenous and exogenous factors influencing the organizational activities;

- the expected results.

In other words, the theory of change permits managers to structure the impact investment and to better promote their intervention and its potential impact on and to different stakeholders by connecting the performed activity with the output, outcome and finally the impact. This type of approach is particularly appropriate in addressing the relevance of the generated impact given the financial capacity of the investment.

Using the theory of change model, the data about steps and activities performed along with the actually obtained results can be confronted with expected results. Thus, the comparison enables managers to examine and evaluate the impact as well as the accuracy of the model (Funnell \& Rogers 2011). The evaluation can usefully guide managers and investors to detect possible anomalies and to take action in order to improve the outcome.

Such an approach does not exclude the possibility to use other methods in parallel, demonstrating thereby flexibility, while being a rigorous analytical tool. "While there are no 'silver bullets' or panaceas in the practice of evaluation, the concept and tool of the theory of change can and should be an integral and explicit element in the evaluation enterprise in the impact investing industry" (Jackson, 2013).

Clearly, the effectiveness of the theory of change can also be questioned at its core, in asking to what extent does impact investment make a difference and to what extent such a difference can really be detected and measured. It remains challenging to make clear how to integrate the theory of change at different organizational levels and how to make it explicit.

However, there are four important characteristics that seem to be good incentives for actors in the impact investment field to adopt this approach.

First of all, as a logical representation of the dynamics taking place within the organization, this approach provides a systematic, structured and rigorous analysis of the cause and effect interactions in impact investments. The complexity and the interlinked elements encompassed in the process of building an impact investment and developing the social or environmental intervention is argued to be well-covered by the theory of change.

The second is that in a nascent sector like impact investing, checks and balances are important. Investments that publicly communicate their intervention through the theory of change seem to be effectively able to attract potential investors, key actors in the field such as government institutions, financial agencies and key partners that can help leverage the impact of the investment to reach a deeper social and environmental change.

Third, impact investment is a new field in which managers are still at the beginning of the learning curve (So \& Staskevicius, 2015). Using the theory of changes serves as an approach to clearly design the strategy used to address their targeted issues, monitor its phases and adjust them according to the degree of advancement and, finally, it helps to better choose the instruments to proceed in further steps. The theory of change in this context seems to provide a clear vision of the projected impact and the goal to be achieved.

Finally, for impact investments ranking agencies, and evaluation experts, the theory of change is a flexible instrument that can be blended innovatively and proactively with various evaluation tools and implemented at multiple levels to provide insightful findings.

However, the theory of change is at the moment mostly used as a valuation framework. As a matter of fact, by itself, it cannot provide any precise impact measurement. That is why an important point made about its usefulness, is about its flexibility as a tool requiring the support of other indicators and indexes to complete the evaluation process.

Figure 1. Theory of change - indicators

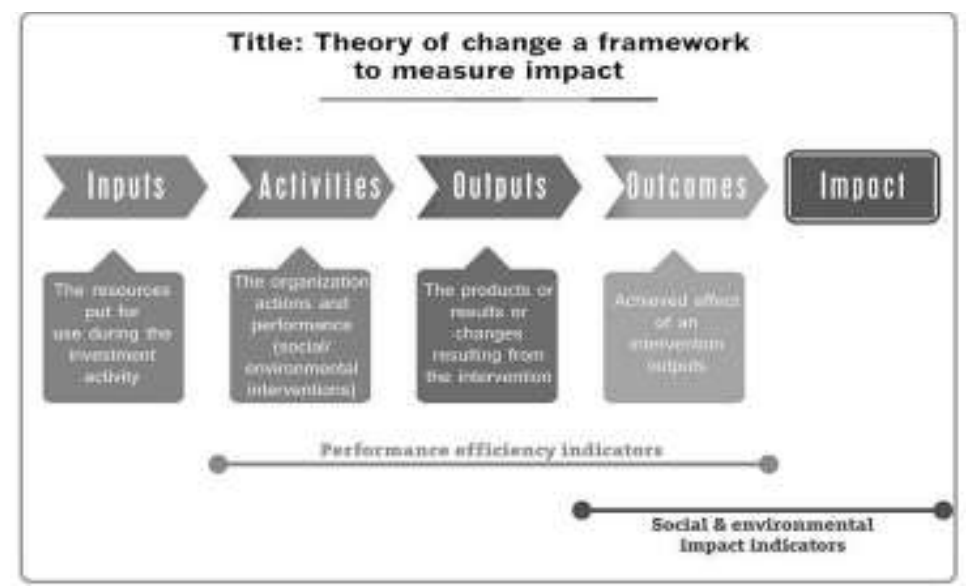




\section{DEFINING METRICS AND APPROACHES TO MEASUREMENTS}

Indicators permit investors and managers of impact investments to perform a series of comparisons between the predefined objectives and the outcomes obtained, comparisons between the outcomes realized during a period and comparisons between the outcomes obtained by different projects in the field of impact investing targeting the same social or environmental need (Molecke \& Pinkse, 2017).

As pointed out in the previous section, complexity is the main source of difficulties against which all the attempts to define a general and effective set of impact metrics fail. However, even though there is no golden standard in measuring social and environmental impact, reports and academic articles examined often cite common measurement tools that are popular in the field. A significant effort has been put in the setting, at least, a few underlying criteria and a certain level of consensus have started to gather around five dimensions impact investment ought to match:

- What: what is the intended impact to be achieved? Collected datasets and information are meant to provide investors and managers with a clear definition of the purposes through the outcome their intervention is generating. It also highlights the significance of the expected outcome and its influence in making the difference. Obtained outcomes are then linked with a strategic target. IRIS+ catalogue has developed a set of metrics that serve as a measurement tool for commonly targeted outcomes associated with organizational goals. The catalogue also offers a set of metrics addressing measurements for the importance of the outcomes. All of them are backed by evidence (GIIN \& IRIS, 2019).

- Who: who are the targeted underserved community or environmental issues? Identify and describe the characteristics of the underserved community to be affected by the intervention, in order to understand the way to bridge their needs gap.

- How much: how many stakeholders are influenced by the outcome generated? How long will it take to make the change? The data covered by this dimension can shed some light on the scale of the intervention and the depth of the impact affecting the stakeholders and the duration taken to have a concrete outcome. Such metrics provide a comparing baseline to a previously defined value and the value of the outcome realized. Hence, the time frame of the intervention enabling the measurement of the time taken to experience the outcome of the impact investment, however, these measurements seem to be very few due to challenges faced in determining how much time the impact will persist which may be an obstacle to building a complete evaluation.

- How efficient: how efficient is the intervention of the investment? The efficiency in fulfilling the targeted community needs is also supposed to be supported by data. These metrics are key tools to compare the performance in terms of depth, time frame, and relevance to the performance of peer benchmarks. In other words, the comparison takes into account the situation of the addressed issue in case of its absence. This dimension reveals, though, a tool scarcity and specific metrics addressing contribution have not been identified yet.

- How risky: what is the likelihood of not reaching the expected impact? The risk factor covers the different types of external and internal risks. Despite the fact that all types of risks are critical, not all risks have the same weight or importance. Consequently, several metrics have been developed, providing a deeper understanding of impact risks but not risk assessment metrics.

In order to disentangle complexity, the most promising approach seems to be to proceed through the understanding and keeping track of progress. In this respect, some steps forward have been made by the so-called Dalberg approach. Dalberg developers have categorized three approaches aiming for global development through private investments; each approach has its level of accountability. The abovementioned approach considers three types of ventures:

1) socially responsible organizations looking for financial returns screening out negative social and environmental negative impact;

2) investments seeking to create a blended value by realizing financial returns through fulfilling social or environmental needs;

3) social enterprises that may not be financially profitable but have sustainability as a priority goal (Olsen \& Galimidi, 2008).

The Dalberg approach is a customized process of performance evaluation based on the theory of change. It considers how investment inputs influence the performed activities. The second phase of the process is to measure the outputs created and the project's capacity to have them become an outcome in the following steps. If successful in making a difference, the outcome generated is then considered and treated as a measurable impact. The final information about the impact resulting at the end of the impact investment value chain is compared to the benchmarks grounded by the performance of traditional businesses. Consequently, the double bottom line can be clearly articulated, measured and evaluated. The challenge in opting for this approach is the high degree of transparency required and the accountability resulting from it.

Another approach, developed by practitioners, is DOTS, Development Tracking System approach. DOTS approach was developed by the International Finance Corporation (IFC) to provide support for newly established businesses at the beginning of their activity, making an impact investment monitoring feasible and supporting the managing team in case of problems becoming easier (Reeder \& Colantonio, 2013).

The methodology relies on a rating system, offering an overall evaluation of the outcome generated on stakeholders by means of a rate to the outcome reached, based on the calculation of a set of indicators. Each project has its own indicators depending on its capacity, activity sector and the scale of its impact, the choice of the indicators is made based on its relevance to the project, its aggregability, ease to use and time boundedness. The assessment is performed periodically, by measuring and rating progress and the achievements the management team has made. The rate encompasses four performance dimensions 
measured by the chosen indicators: financial, economic, social, environmental.

The four dimensions measurement is also synthesized to provide an overall rate of the final outcome on a 6 points scale (Olsen \& Galimidi, 2008).

On the same stream of approaches developed in the industry, there is the HIP framework (Human Impact and Profit). It is an approach designed to measure quantitatively the human, social and environmental impacts and the way they generate a financial return. It also provides guidelines for a sustainable management system that may help maintain financial success in the long run. The HIP approach is based on the argument that boosting positive social impact generates a higher return for the business and strengthens the economic sustainability of the investment (So \& Staskevicius, 2015).

The HIP methodology is also built on the McKinsey framework for strategic consulting, the balanced scorecard and the Social Return on Investment (SROI) ratios seems to be common tools used in various approaches. The initiative of developing the HIP framework started with the aim of deeply analyzing the environmental impact and eventually ranking global leaders in the energy industry, the approach has been then developed to become a cross-sector approach.

The main characteristic of this methodology is that it can be adopted by impact investors to establish their investment strategy, to efficiently allocate their assets and to build their investment portfolios. The HIP framework is a result-oriented approach, measuring five aspects of the impact an organization has on its stakeholders (employees, customers, suppliers etc.). These quantifiable aspects are divided among social aspects: health, wealth, equality and trust and environmental aspect.

The HIP has been developed to demonstrate the extent to which boosting net positive human impact may generate higher financial revenues and lower costs. Moreover, this framework is applied to evaluate and assess the management system of the organization, as a matter of fact, it focuses on five management features that, when enhanced, can drive sustainability and profitability as well (Reeder \& Colantonio, 2013):

- mission and vision;

- decision making;

- evaluation and assessment;

- transparency and accountability;

- financial alignment.

HIP measurement methodology combines both company interviews and secondary data research. The final result is a multidimensional rate of the company, considering at one time the social and environmental impacts, the management practices and its systematically evaluated sustainability and, finally, focus on profitability and financial returns. The HIP framework is more used in a comparison with competitors in the same industry giving insightful findings of the attractiveness of the investment for a financial portfolio.

One further approach is known as the Social Impact Assessment (SIA). It presents several analogies with previously presented approaches and it focuses on financial tools. SIA approach has a good reputation among assessing models and its adoption is a requirement for entrant start-up businesses and innovative impact projects participating in the Global Social Venture Competition (GSVC).

In double bottom line investments, generally managers report the social impact using the SROI approach. In practice, the SIA approach follows the SROI framework in defining the impact the organization is aiming to realize, measuring and evaluating the outcome of the performed intervention and reporting and documenting the impact achieved (Olsen \& Galimidi, 2008).

However, the difference between the two methods lies in the scope of the intervention: unlike SROI, the SIA framework recommends restricting the scope of the analysis per-formed to the top impact priorities the organization is chasing. The second difference is the definition of the stakeholders impacted: the social impact assessment approach does not specify the definition of the stakeholders included in the evaluation process

SIA methodology seems to be more rigorous than the previous methodologies since it articulates the analysis in three major phases:

1. It defines the social or environmental value created by the means of the theory of change.

2. It quantifies the impact generated by measuring preselected indicators which are considered highly correlated with the outcomes, systematically trackable as a part of the business operations.

3. It expresses the impact in terms of currency value, using money as a unit of measurement of the impact generated by the investment (Olsen \& Galimidi, 2008).

SIA guidelines recommend the use of the theory of change as a framework that would later help specify the inputs required to perform organizational operations, the measurable outputs obtained and the evaluation of the outcome or change resulting from the organizational intervention. Taking advantage of this, managers can prioritize the measurable outcomes and identify the indicators able to track the organizational activities correlated with the addressed outcome. As a final step, "SIA directs entrepreneurs to assign a monetary value to outcomes as a final step prior to preparing a discounted "social cash flow analysis" of these values. Since no standard discount rate for such a calculation exists, SIA advises entrepreneurs to determine a discount rate using their own logic" (Olsen \& Galimidi, 2008).

Concluding this brief and possibly incomplete recognition of the most used approaches employed in the industry to assess impact investment metrics, the SROI Approach has to be mentioned.

Social Return on Investment is frequently cited among measurement methods examined (BankeThomas, Madaj, Charles, \& van den Broek, 2015). It is actually a measurement and accounting framework characterized by a broader concept of value that goes beyond solely the financial value, as the definition of impact investment itself implies the enhancement of a positive impact by incorporating social and environmental costs and benefits.

The social impact is captured through the changes measured by the SROI in a way that is appropriate to stakeholders that experienced it or contributed to its creation. SROI calculation per se, 
actually tells the story of the value enhancement and the change brought to the targeted community by using monetary values to quantify and represent environmental and social outcomes.

The adoption of such a tool enables managers to calculate a benefit to cost ratio, however, SROI is more value rather than a mere financial tool. The use of money is justified by the fact that money is a common unit, which makes it widely accepted and easy to adopt measurement frameworks (Best \& Harji, 2012).

SROI is multidimensional, it can be implemented on one hand as an evaluating framework that focuses its measurement on the actual generated outcomes. On the other hand, it can be implemented as a forecast framework, which enables investors and managers to predict the extent to which the organization can generate a further positive social value if the expected outcome goal is achieved.

The usefulness of the forecast dimension lies in the need for a tool that helps predict the changes in order to efficiently plan and establish a suitable strategy to follow. SROI provides findings of the alternatives to maximize the impact created and optimize the in-vestments' financial return.

\section{CONCLUSION}

While examining the measurement approaches, frameworks, and metrics, one important difficulty was highlighted in evaluating the social and environmental impact. That is to say the monetarization and the estimation of the intangible impact generated by the investment.

The aim of the measurement section is to expose the most used and known measurement tools and the used methodology of each. However, up to now no extensive empirical study has been done and published, from this point of view, this paper is not an exception. Such a gap may be related to the novelty of the topic, but mainly it is probably more related to the difficulties in collecting suitable data. Data are, in fact, very fragmented and impact varies over time, depending on many variables.

Whatever measurement tool will be established, it will not be able to fully reflect and transmit the real value of the social and environmental impact generated. The core limitation of all papers and researches so far published in this field is that they are trying to quantify the unquantifiable.

The evaluation of the measurement tools was not empirically tested in the paper and has not been elsewhere, as far as it was possible to find out in this paper.

Finance has developed sophisticated tools and metrics to assess the performance of in-vestments and portfolios. An update for the modern portfolio theory is crucial in the context of impact investing and a three-dimensional evaluation model, integrating impact in the traditional risk/expected return model should be established to facilitate the decision-making process, since in impact investment where the social and environmental return on investment is as important as the financial return, academia is still struggling between two approaches.

Scholars like Mulgan, argue against the development of a single metric or indicator of performance. His argument is based on the fact that one single matric does not show explicitly social performance, unlike scoring methods that balance the blended value of financial and social performance.

Criticism of Social Return on Investment is based on the fact that this approach relies on the monetarization of social and environmental impacts. Although the SROI method has enhanced the act of monetarization as a tool to converge units of measurement toward the use of money, some studies claim that this conversion relies on subjective estimations.

This evaluation may be inconsistent with the aim of investors to compare the social or environmental impacts across companies in the same industry, which may mislead evaluations.

Another criticism worth mentioning concerns the risk of these investments. The explored measurements focus on measuring the social or environmental outcome as an approach to measure the impact. In spite of the volatility of social outcomes due to the political, economic and social dynamism, these approaches do not investigate the level of risk associated with the volatility of outcomes related to the social and human interactions.

Future research should step forward to explore different ways to treat metrics rather than looking for new metrics. Social and human phenomena very quickly in response to environmental changes, which are the expected results of impact investments, therefore over time, become tricky to understand whether the change is an effect of the investment or its cause.

A new approach should integrate this idea and start developing a simple index of positivity, and only afterward starting to define a more precise metric for impact. Such attempts are already in place and will probably give results soon.

\section{REFERENCES}

1. Banke-Thomas, A., Madaj, B., Charles, A., \& van den Broek, N. (2015). Social Return on Investment (SROI) methodology to account for value for money of public health interventions: a systematic review. BMC Public Health, 15(1). https://doi.org/10.1186/s12889-015-1935-7

2. Best, H., \& Harji, K. (2019). Guidebook for impact investors: Impact measurement. Toronto, Canada: Purpose Capital.

3. Costa, E., \& Pesci, C. (2016). Social impact measurement: Why do stakeholders mater? Sustainability Accounting, Management and Policy Journal, 7(1), 99-124. https://doi.org/10.1108/SAMPJ-12-2014-0092

4. Freeman, H. E., \& Sherwood, C. C. (1965). Research in large-scale intervention programs. Journal of Social Issues, 21(1), 11-28. https://doi.org/10.1111/j.1540-4560.1965.tb00480.x

5. Funnell, S. C., \& Rogers, P. J. (2011). Purposeful program theory: Effective use of theories of change and logic models. San Francisco, CA: Jossey-Bass. Retrieved from https://assets.thalia.media/doc/c8/a9/c8a90e5b-54a34a04-84c9-d0db38fba2f0.pdf 
6. Galilei, G. (1632). Dialogo sopra i due massimi sistemi del mondo tolemaico e copernicano.

7. Global Impact Investing Network (GIIN). (2017). Annual impact investor survey. Retrieved from https://thegiin.org/assets/GIIN_AnnualImpactInvestorSurvey_2017_Web_Final.pdf

8. Global Impact Investing Network, \& IRIS. (2019). IRIS + and the five dimensions of impact. Retrieved from https://iris.thegiin.org/document/iris-and-the-five-dimensions/

9. Grabenwarter, U., \& Liechtenstein, H. (2011). In search of gamma - an un-conventional perspective in impact investing (IESE Business School Working Paper). https://doi.org/10.2139/ssrn.2120040

10. Greenberg, B. G., \& Mattison, B. F. (1955). The whys and wherefores of program evaluation. Canadian Journal of Public Health/Revue Canadienne de Sante'e Publique, 46(7), 293-299. Retrieved from https://www.jstor.org/stable/41980670

11. Harari, N. (2016). Homo deus. Breve storia del Futuro. Bompiani.

12. Harji, K., \& Jackson, E. T. (2012). Accelerating impact: Achievements, challenges and what's next in building the impact investing industry. New York, USA: The Rockefeller Foundation. Retrieved from https://assets.rockefellerfoundation.org/app/uploads/20120707215852/Accelerating-Impact-FullSummary.pdf

13. Hochstadter, A. K., \& Scheck, B. (2015). What's in a name: An analysis of impact investing understandings by academics and practitioners. Journal of Business Ethics, 132, 449-475. https://doi.org/10.1007/s10551-0142327-0

14. Jackson, E. (2013). Interrogating the theory of change: Evaluating impact investing where it matters most. Journal of Sustainable Finance \& Investment, 3(2), 95-110. https://doi.org/10.1080/20430795.2013.776257

15. Lévêque, J., Levillain, K., \& Segrestin, B. (2018). Réalisation de l'impact ou génération d'alternatives? Une étude des méthodes d'évaluation de l'investissement à impact. Retrieved from https://hal.archives-ouvertes.fr/hal01897420 /document

16. Maas, K., \& Liket, K. (2011). Social impact measurement: Classification of methods. Environmental Management Accounting and Supply Chain Management, 171-202. https://doi.org/10.1007/978-94-007-1390-1_8

17. Molecke, G., \& Pinkse, J. (2017). Accountability for social impact: A bricolage perspective on impact measurement in social enterprises. Journal of Business Venturing, 32(5), 550-568. https://doi.org/10.1016/j.jbusvent.2017.05.003

18. Mulgan, G. (2010). Measuring social value. Stanford Social Innovation Review, 8(3), 38-43. Retrieved from https://ssir.org/articles/entry/measuring_social_value

19. Nicholls, A., \& Tomkinson, E., (2015). Risk and return in social finance: "I am the market". In Social Finance. Oxford University Press. https://doi.org/10.1093/acprof:oso/9780198703761.001.0001

20. Olsen, S., \& Galimidi, B. (2008). Catalog of approaches to impact measurement: Assessing social impact in private ventures Version 1.1. Retrieved from http://www.midot.org.il/Sites/midot/content/File/ CATALOG\%20OF\%20APPROACHES\%20TO\%20IMPACT\%20MEASUREMENT(1).pdf

21. Ormiston, J., Charlton, K., Donald, M., \& Seymour, R. (2015). Overcoming the challenges of impact investing: Insights from leading investors. Journal of Social Entrepreneurship, 6(3), 352-378. https://doi.org/10.1080/19420676.2015.1049285

22. Perret, B. (2008). L'évaluation des politiques publiques. Esprit, 12, 142-159. https://doi.org/ $10.3917 /$ espri.812.0142

23. Reeder, N., \& Colantonio, A. (2013). Measuring impact and non-financial returns in impact investing: A critical overview of concepts and practice (EIBURS Working Paper 2013/01, London School of Economics and Political Science). Retrieved from https://lsecities.net/wp-content/uploads/2013/10/Measuring_Impact-full-length-Oct20131.pdf

24. Rizzello, A., Caré, R., Migliazza, M. C., \& Trotta, A. (2016). Social impact investing: A model and research agenda. In O. Lehner (Ed.), Routledge Handbook of Social and Sustainable Finance. Routledge. https://doi.org/10.4324/9781315772578.ch7

25. Schinckuns, C. (2017). The valuation of social impact bonds: An introductory perspective with the Peterborough SIB. Research in International Business and Finance, 45, 1-6. https://doi.org/10.1016/j.ribaf.2017.07.126

26. So, I., \& Staskevicius, A. (2015). Measuring the "impact" in impact investing (Report, Harvard Business School). Retrieved from http://www.hbs.edu/socialenterprise/documents/measuringimpact.pdf

27. Spiess-Knafl, W., \& Scheck, B. (2017). Impact investing: Instruments, mechanism and actors. Palgrave. https://doi.org/10.1007/978-3-319-66556-6

28. Stievenart, E., \& Pache, A. (2014). Evaluer l'impact social d'une entreprise sociale: Points de repère. Revue internationale de l'économie sociale, 331(93), 76-92. Retrieved from http://recma.org/sites/default/ files/recma331_076092.pdf 